\title{
Quality of life of insulin-naïve people with type 2 diabetes mellitus inadequately controlled on oral antidiabetic drugs after the addition of insulin glargine, in every day clinical practice in Greece
}

\begin{abstract}
Objectives: To assess the quality of life (QoL) of insulin-naïve people with Type 2 Diabetes Mellitus (T2DM) inadequately controlled on oral antidiabetic drugs (OADs)) after the addition of insulin glargine through the use of self-reported questionnaires (ADDQoL, DTSQs and DTSQc).

Design: Insulin-naïve Greek patients with T2DM $>1$ year inadequately controlled on at least 2 OADs as assessed by HbAlc between $7.0 \%-9.0 \%$ were recruited. The addition of insulin glargine to the treatment was initiated within one month prior to enrollment and patients were evaluated at the beginning of the study and at 3 and 6 months through $\mathrm{HbAlc}$ measurements and self-reported quality of life questionnaires. Data were analyzed using descriptive statistics.
\end{abstract}

Results: HbA1c (\%) \pm SD decreased from $8.3 \pm 0.5$ to $7.4 \pm 0.7$ and $7.2 \pm 0.6$ at 3 and 6 months, respectively $(p<0.001)$. No significant changes in symptomatic hypoglycemia and no severe hypoglycemia were reported. Concerning the ADDQoL-19, the "present" QoL score improved from $0.42 \pm 0.97$ to $0.79 \pm 0.81$ and $0.93 \pm 0.82(p<0.001)$, the "If no Diabetes" QoL score decreased from $-1.50 \pm 0.78$ to $-1.51 \pm 0.78$ and increased to $1.42 \pm 0.80(p=0.03)$ and the "Average Weighted Impact-AWI" score improved from $-2.48 \pm 1.83$ to $-2.46 \pm 1.67$ and $-2.35 \pm 1.71$ at 3 and 6 months, respectively $(p=0.03)$. The $\mathrm{DTSQ}_{\mathrm{S}}$ score improved from $22.58 \pm 7.13$ to $26.34 \pm 6.51$ and $27.10 \pm 6.86(p<0.001)$ while perceived frequency of hypo/ hyperglycaemia decreased from $5.22 \pm 1.89$ to $3.82 \pm 2.11$ and $3.20 \pm 2.12$ at 3 and 6 months, respectively $(p<0.001)$. The $\mathrm{DTSQ}_{\mathrm{C}}$ score at 6 months was $11.45 \pm 6.70(p<0.001)$, while the respective hypo/hyperglycaemia score was $-2.74 \pm 2.73(p<0.001)$.

Conclusion: The improved glycaemic control as assessed by HbAlc values, achieved by the addition of insulin glargine to the treatment of patients with T2DM inadequately controlled with OADs resulted in a positive impact on QoL and treatment satisfaction (TS) with reduced perception of hypo/hyperglycaemia.

Keywords: type 2 diabetes mellitus, insulin glargine, glycaemic control, hypoglycaemia, quality of life, treatment satisfaction
Volume 2 Issue 2 - 2015

\author{
Georgios Koukoulis,' Andreas Melidonis, ${ }^{2}$ \\ Kostas Milios, ${ }^{3}$ Mellita Investigators \\ 'University Clinic of Endocrinology and Metabolic Diseases, \\ University Hospital of Larisa, Greece \\ ${ }^{2}$ Diabetic Centre, Outpatient Clinic, General Hospital of Piraeus \\ Tzaneio Greece \\ ${ }^{3}$ Sanofi, Medical Department, Greece
}

Correspondence: Georgios Koukoulis, University Clinic of Endocrinology and Metabolic Diseases, University Hospital of Larisa, Larisa, Greece, Tel +3024 I350 2820, Email gnkouk@med.uth.gr

Received: February 18, 2015 | Published: May 20, 2015
Abbreviations: T2DM, type 2 diabetes mellitus; OADs, oral antdiabetic drugs; ADDQoL, audit of diabetes dependent quality of life; DTSQs/c, diabetes treatment satisfaction questionnaire status/ change; QoL, quality of life; TS, treatment satisfaction

\section{Introduction}

Quality of Life (QoL) is quantitated by assessing physical and social functioning and perceived physical and mental well-being. It is an important health outcome in its own right, representing the ultimate goal of all health interventions. QoL is of particular concern to those patients with chronic diseases. Type 2 diabetes mellitus (T2DM) is a chronic disease and is associated with short-term and long-term complications which can negatively affect patients' well-being, health status and QoL. Compared to persons without diabetes, most studies reported worse QoL for people with diabetes, especially regarding physical functioning and wellbeing. ${ }^{1,2}$
Diabetes places a significant burden upon health related quality of life (HRQoL), with patients experiencing a reduction in both total and health life years as a result of disability and related comorbidities. Additional challenges arise during the management of diabetes, where the fear of hypoglycaemia, fear of insulin injections and complex treatment regimens are major concerns among patients and have an impact on QoL. The relationship between QoL and diabetes is bidirectional; aspects of diabetes may negatively impact QoL and impaired QoL may also negatively influence diabetes self-management and thus health outcomes and treatment satisfaction (TS). ${ }^{3}$

Diabetes therapy such as receiving insulin has the potential to affect QoL in both negative and positive ways. Clearly, QoL can be impeded by concerns about needles/pain, hassles of frequent injections, fears and episodes of hypoglycaemia, weight gain, and other potential adverse events. On the other hand, improved glycaemic control can have positive ramifications and also reduce diabetic complications. ${ }^{4}$ Consequently, it is essential to assess whether the optimal glycaemic 
control (defined as $\mathrm{HbAlc} \leq 7 \%$ ) that can be achieved by antidiabetic treatments impacts TS and QoL. ${ }^{1,5}$

A common therapeutic intervention for patients with T2DM inadequately controlled on OADs, is the initiation of insulin therapy with long-acting basal insulin analogues, such as insulin glarginep. Several clinical trials demonstrated efficacy of insulin treatment in insulin-naïve patients and favourable effects on HRQoL. ${ }^{5,7,8}$ However, for patients with T2DM starting a long-acting insulin as an add-on treatment on OADs in Greece, data on the effect on QoL indices are limited or poorly documented.

The aim of this prospective, observational, non-interventional ${ }^{9}$ study (MELLITA) was to evaluate the effect of improved glycaemic control achieved by the addition of insulin glargine on the QoL indices of patients with T2DM, inadequately controlled on OADs, in everyday clinical practice in Greece, through self- completion of validated QoL questionnaires (ADDQoL, DTSQc and DTSQs)

\section{Materials and methods}

\section{Study design}

This multicentre, 6 month, prospective, observational, noninterventional, cohort study was conducted in 20 sites (in hospital or primary care setting and in private clinics) in Greece between March 2010 and May 2013. The sites selection was performed following a country feasibility questionnaire, capturing a degree of representativeness of the daily management of patients with T2DM. Each centre recruited 23 consecutive persons according to inclusion and exclusion criteria. The study protocol was approved by hospitals' scientific committees and by National Organization of Medicines and conducted in accordance with the Declaration of Helsinki.

\section{Study population}

Insulin naïve patients with T2DM in sub-optimal control $(7.0 \%$ $<\mathrm{HbA} 1 \mathrm{c}<9.0 \%$ ) were eligible. Inclusion criteria included: Patients with T2DM and duration for at least 1 year, age of 18 years or older, on at least 2 OADs (Sulphonylurea-SU- at least $1 / 2$ maximum doses and metformin $\geq 1.5 \mathrm{~g}$ per day or lower if not tolerated), clinical need to initiate insulin glargine within the last month before enrolment and completion of informed consent by the patients. Insulin glargine was thus initiated as part of routine care and current practice, at the discretion and the clinical judgment of the treating physician. Exclusion criteria included patients less than 18years, pregnant or lactating women. The study did not interfere with clinical practice and only required completing a questionnaire booklet provided to the individual by the treating physician at three consecutive periodic consultations. Clinical data were retrieved from the medical records. Blood samples were collected and measured locally as part of routine care by the participating centres. Guidelines were given by treating physicians to patients to be 10-12hours fast in order to perform blood tests. The insulin titration schedule and diet modification was also according to the clinical judgement of the participating physicians.

Demographic and clinical data obtained at baseline, 3 and 6months included time since diagnosis, tobacco use, previous and current medication, presence of diabetes-related complications and comorbidities, HbAlc and Fasting Blood Glucose (FBG) and relevant changes in the treatment regimens, as well as any adverse events.

511 consecutive patients conforming to the inclusion criteria were recruited. However 75 appeared not to be sub optimally controlled
$(<7.0 \%$ or $>9.0 \%)$ and excluded from the analysis, resulting in a study population of 436 participants (Figure 1). 415 out of 436 participants (95.2\%) completed the study and 21(4.8\%) dropped out. Out of 21 patients that dropped out the study, 6 patients dropped the study at 3 months between V1 and V2 and 15 patients dropped out at 6 months between V2 and V3. Data were analysed for the number of visits that each patient performed.

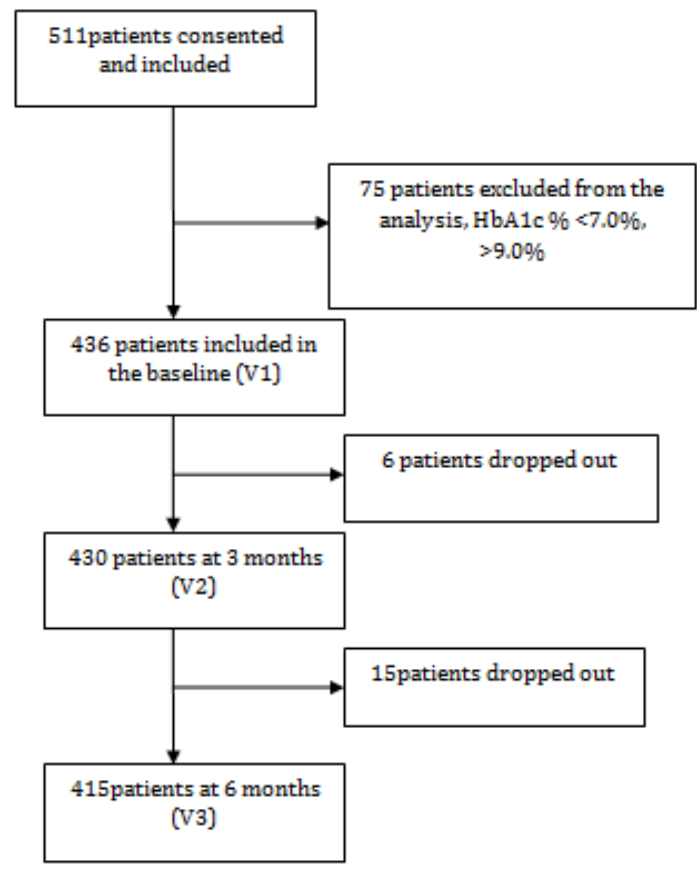

Figure I Study flow chart.

Prior to initiating insulin glargine, $88.1 \%$ of patients $(n=384)$ received metformin, $95.4 \%(\mathrm{n}=416)$ received $\mathrm{SU}, 22.9 \%(\mathrm{n}=100)$ received thiazolidinediones-TZDs and $27.1 \%(\mathrm{n}=118)$ received Dipeptyl-Peptidase-IV (DPP-IV) inhibitors or fixed combination of DPP-IV inhibitors and metformin, whereas $6.0 \%(n=26)$ received repaglinide or nateglinide and alpha-glucosidase inhibitors.

At initiation of insulin glargine, $75.0 \%$ of patients $(n=327)$ reported co-medication with metformin and $63.1 \%(\mathrm{n}=275)$ reported co-medication with SU.

$3.0 \%(\mathrm{n}=13)$ received co-medication with TZDs and $20.0 \%(\mathrm{n}=87)$ received co-medication with DPP-IV inhibitors or fixed combination of DPP-IV inhibitors and met for min. 9.9\%(n=43) reported comedication with repaglinide or nateglinide and alpha-glucosidase inhibitors and $0.9 \%(n=4)$ received other treatment.

\section{Objectives and safety measurements}

The primary objective was the evaluation of QoL and diabetes TS through change in both ADDQoL and DTSQ scores from baseline to study end. Secondary objectives included: percentage of patients with $\mathrm{HbAlc}<7 \%$ after 6months, mean change in $\mathrm{HbAlc}$, body weight and BMI, number of documented hypoglycaemic episodes (severe and non-severe), mean insulin dose and mean change in insulin dose from baseline to study end. Safety was assessed by solicited reporting and adverse events were defined according to Guidelines for Good Epidemiology Practice (GEP) proper conduct in epidemiology research. ${ }^{10,11}$ Documented symptomatic hypoglycaemia was defined as an event of typical symptoms of hypoglycaemia, such 
as palpitations, tremor, hunger, sweating or confusion, accompanied by a measured plasma glucose concentration $\leq 70 \mathrm{mg} / \mathrm{dl}(3.9 \mathrm{mmol} / \mathrm{l})$. Severe hypoglycaemia was defined as symptomatic hypoglycaemia in which the assistance of another person and/or an injection of glucagon were necessary to treat it, ${ }^{6,12}$ Patients measured their blood glucose concentrations by glucometers and self-reported hypoglycaemic episodes at 3 and 6 month visits.

\section{Assessment of diabetes dependent quality of life and diabetes treatment satisfaction}

The same self-administered QoL and DTSQ validated and reliable psychometric questionnaires by Health Psychology Research (HPR), Department of Psychology, and University of London ${ }^{13}$ were completed at baseline, 3 and 6 months. The HPR specializes in the development and use of Patient-Reported Outcome measures in diabetes research and have been used in previous studies that accessed TS and QoL. ${ }^{78}$ A licence agreement before using the questionnaires was obtained by the study sponsor.

Diabetes Dependent Quality of Life was evaluated using the Audit of Diabetes-Dependent Quality of Life (ADDQoL-19) questionnaire, designed to measure patients' perception of the impact of diabetes on their QoL which included 2 introductory questions and 19 aspects of life, assessing patient's perspective, how much better his or her life would be if they did not have diabetes and how important each of these 19 aspects were per individual.

The ADDQoL included two items; one assessed 'present' QoL with values ranging from -3 to +3 and the second assessed the 'impact of diabetes on' QoL ('if no Diabetes' QoL would be) with values ranging from -3 to +1 . Lower scores reflected poorer QoL. Participants also rated the impact of diabetes (negative to positive, range -3 to +1 ) on each of 19 aspects and the importance (range 0 to +3 ) of each aspect for their QoL. Impact score was multiplied by the importance to yield a weighted impact score for each aspect (range -9 to +3). An Average Weighted Impact (AWI) score was also calculated for the entire scale by averaging across all applicable aspects of QoL (range -9 to +3 ) combining their importance to patients with their impact. ${ }^{13}$

TS was collected using the DTSQ, the "status form" of the questionnaire $\left(\mathrm{DTSQ}_{\mathrm{S}}\right)$, which measured satisfaction score at baseline, 3 and 6months and the "changed version" of the questionnaire $\left(\mathrm{DTSQ}_{\mathrm{C}}\right.$ ), which measured the month 6 minus baseline DTSQ scores. The DTSQs contained 8 questions with values ranging from 0 to 6 and measured TS Scores (six questions, Qs.1 and 4-8), Perceived Frequency of hyperglycaemia (Qs.2) and Perceived Frequency of hypoglycaemia (Qs.3) over the past 12 weeks. In each time point, two scores were calculated:

i. The TS Score (ranging from 0 to +36 , the higher the score, the greater the satisfaction)

ii. The perceived frequency of hypo/hyperglycaemia (ranging from 0 to +6 , the lower score indicates blood glucose levels closer to the ideal)

iii. The DTSQc contained the same 8 questions as $\mathrm{DTSQ}_{\mathrm{S}}$ with values ranging from -3 to +3 .

iv. In each time point, two scores were calculated: The TS Score (ranging from -18 to +18 , the higher the score, the greater the improvement in satisfaction) v. The perceived frequency of hypo/hyperglycaemia (ranging from -3 to +3 , negative scores indicate fewer problems with blood glucose levels; positive scores indicate more problems than before). Values close to zero indicate no change. ${ }^{13}$

\section{Sample population size}

Sample size estimation was based on HbA1c improvement and the expected percentage of patients achieving target $\mathrm{HbA} 1 \mathrm{c}<7 \%$ at month 6 . We based our calculation on the \% of patients at target, as this has been found, to be a good marker to estimate the sample size needed to detect an effect on these questionnaires. ${ }^{14}$ The expected proportion of patients with $\mathrm{HbA} 1 \mathrm{c}<7 \%$, would range from $26 \%$ to $30 \%$, according to relevant study. ${ }^{15,16}$ Having in mind that the final sample size would be $400-600$ patients, the main target was to minimize the maximum accepted error in the estimation of the above proportion, using a reasonable sample size.

Thus we examined the required sample size as a function of the above proportion, for different errors $(3 \%, 4 \%$ and $5 \%)$. A final sample size of approximately 500 patients would ensure a maximum error below $4 \%$ for the range of possible proportions of patients with $\mathrm{HbA} 1 \mathrm{c}<7 \%$. The final sample size was 415 patients at 6 months with a maximum error below $5 \%$.

\section{Statistical analysis}

Descriptive statistics was used. The Statistical measures were frequencies and distribution percentages for discrete variables and descriptive measures (mean, median, maximum, minimum, standard deviation) for continuous variables. Statistical tests among discrete variables were implemented by using the test Chi-Square $\left(\chi^{2}\right.$ test). For statistical tests of discrete variables with two categories each $(2 \times 2$ tables), the Fisher Exact Test was used. The t-test was used for the comparison of values of continuous variables between two categories of discrete variables and the Anova F-Test for the comparison among more than two categories of discrete variables. For comparison of values over time, the non-parametric Friedman test was used to compare between more than two categories of discrete values and Wilcoxon test for comparison among two value categories. Paired T tests were used for comparisons between endpoint versus baseline for the same subject. The Pearson product-moment correlation coefficient (r) was used to measure the linear correlation between Quality of life ADDQoL-19 indices and glycaemic control. All statistical analyses were implemented at a significance level of $\alpha=0.05$ by using the statistical package SPSS version 16.0.

\section{Results and discussion}

\section{Baseline characteristics}

Baseline, 3 and 6 months population characteristics, antidiabetic and other treatment, diabetic complications, comorbidities and changes in clinical outcomes over time are shown in Table 1.

\section{Concomitant treatment}

Throughout the study, no significant changes were observed in the co-administration of the antidiabetic and other treatment as shown in Table 1.

$8.9 \%$ of patients $(n=39)$ received mealtime rapid acting insulin as combination therapy at initiation of insulin glargine and increased to $14.4 \%$ and $17.6 \%$ at 3 and 6 months. 
Table I Baseline, 3 and 6 months population characteristics, antidiabetic and other treatment and changes in clinical outcomes of the study population over time

\begin{tabular}{|c|c|c|c|c|c|c|}
\hline & $\begin{array}{l}\text { Baseline } \\
(n=436)\end{array}$ & $\begin{array}{l}3 \text { Months } \\
(n=430)\end{array}$ & $\begin{array}{l}6 \text { Months } \\
(n=4 \mid 5)\end{array}$ & $\begin{array}{l}\text { P Baseline } \\
-3 \text { Months }\end{array}$ & $\begin{array}{l}\text { P } 3 \text { Months } \\
-6 \text { Months }\end{array}$ & $\begin{array}{l}\text { P Baseline } \\
-6 \text { Months }\end{array}$ \\
\hline Age (Years) $\pm S D$ & $65 \pm 11$ & & & & & \\
\hline Male/Female & $207 / 229$ & $203 / 227$ & $200 / 215$ & & & \\
\hline Duration Of Diabetes (years) \pm range & $10(6-15)$ & & & & & \\
\hline $\mathrm{BMI}(\mathrm{kg} / \mathrm{m} 2) \pm \mathrm{SD}$ & $30.1 \pm 5.3$ & $30.2 \pm 5.3$ & $30.0 \pm 5.2$ & 0.603 & 0.603 & 0.623 \\
\hline Weight $(\mathrm{kg}) \pm S D$ & $81.2 \pm 15.3$ & $81.4 \pm 15.0$ & $81.4 \pm 14.6$ & 0.295 & 0.295 & 0.265 \\
\hline $\mathrm{HbAlc}(\%) \pm \mathrm{SD}$ & $8.3 \pm 0.5$ & $7.4 \pm 0.7$ & $7.2 \pm 0.6$ & $<0.001$ & $<0.001$ & $<0.001$ \\
\hline Fasting Blood Glucose $(\mathrm{mg} / \mathrm{dl}) \pm \mathrm{SD}$ & $189 \pm 43$ & $137 \pm 30$ & $128 \pm 32$ & $<0.001$ & $<0.001$ & $<0.001$ \\
\hline \multicolumn{2}{|c|}{$\begin{array}{l}\text { Hypoglycaemic episodes - Symptomatic } \\
\text { (Based On Self-Report) }\end{array}$} & $2.5 \pm 2.1$ & $2.1 \pm 2.4^{*}$ & & 0.673 & \\
\hline \multicolumn{2}{|l|}{$\mathrm{n}, \% 0$ Episodes } & 392(91\%) & $383(92 \%)$ & & 0.168 & \\
\hline \multicolumn{2}{|l|}{ n,\% I Episode } & $13(3 \%)$ & $20(5 \%)$ & & & \\
\hline \multicolumn{2}{|l|}{ n,\% 2 Episodes } & $14(3 \%)$ & $6(4 \%)$ & & & \\
\hline \multicolumn{2}{|l|}{ n,\% 3 Episodes } & $4(1 \%)$ & $2(1 \%)$ & & & \\
\hline \multicolumn{2}{|l|}{$\mathrm{n}, \% \geq 4$ Episodes } & $7(2 \%)$ & $4(1 \%)$ & & & \\
\hline \multicolumn{2}{|l|}{ Hypoglycaemic episodes - severe } & - & - & & & \\
\hline \multicolumn{2}{|l|}{$\mathrm{n}, \% 0$ Episodes } & $430(100 \%)$ & $415(100 \%)$ & & - & \\
\hline \multicolumn{2}{|l|}{ n,\% I Episode } & 0 & 0 & & - & \\
\hline \multicolumn{2}{|l|}{$\mathrm{n}, \% \geq 2$ Episodes } & 0 & 0 & & - & \\
\hline \multicolumn{7}{|l|}{ Antidiabetic Treatment } \\
\hline$\%$ Metformin & $75.0 \%$ & $75.3 \%$ & $76.9 \%$ & & & \\
\hline \% Sulfonyluria & $63.1 \%$ & $58.4 \%$ & $53.5 \%$ & & & \\
\hline \% Nateglinide or Repaglinide & $4.4 \%$ & $5.3 \%$ & $5.5 \%$ & & & \\
\hline \% Thiazolidinediones & $3.0 \%$ & $3.0 \%$ & $3.1 \%$ & & & \\
\hline \% Alpha Glycosidace Inhibitors & $5.5 \%$ & $3.5 \%$ & $3.9 \%$ & & & \\
\hline \% DPP-IV Inhibitors & $20.0 \%$ & $24.2 \%$ & $25.3 \%$ & & & \\
\hline$\%$ Other & $0.9 \%$ & $1.2 \%$ & $1.0 \%$ & & & \\
\hline \multicolumn{7}{|l|}{ Other Treatments } \\
\hline Beta Blocker & $29.8 \%$ & $29.5 \%$ & $30.1 \%$ & & & \\
\hline Calcium Channel Blocker & $31.0 \%$ & $30.5 \%$ & $32.0 \%$ & & & \\
\hline Diuretic & $37.4 \%$ & $36.7 \%$ & $37.1 \%$ & & & \\
\hline $\begin{array}{l}\text { ACE -Inhibitor or Angiotensin - } \\
\text { Converting - Enzyme Inhibitor }\end{array}$ & $69.3 \%$ & $71.6 \%$ & $71.3 \%$ & & & \\
\hline Nitrates & $6.9 \%$ & $6.0 \%$ & $7.0 \%$ & & & \\
\hline Statins & $67.4 \%$ & $69.1 \%$ & $71.1 \%$ & & & \\
\hline Fibrate & $1.6 \%$ & $2.8 \%$ & $3.1 \%$ & & & \\
\hline Anti Platelet Agent & $47.2 \%$ & $48.1 \%$ & $48.4 \%$ & & & \\
\hline Other & $26.4 \%$ & $24.0 \%$ & $22.4 \%$ & & & \\
\hline Diabetic Complications** & & & & & & \\
\hline \% Chronic Renal Failure & $11.8 \%$ & - & - & & & \\
\hline \% Microalbuminuria & $25.5 \%$ & - & - & & & \\
\hline
\end{tabular}


Table Continued...

\begin{tabular}{|c|c|c|c|c|c|c|}
\hline & $\begin{array}{l}\text { Baseline } \\
(n=436)\end{array}$ & $\begin{array}{l}3 \text { Months } \\
(n=430)\end{array}$ & $\begin{array}{l}6 \text { Months } \\
(n=415)\end{array}$ & $\begin{array}{l}\text { P Baseline } \\
-3 \text { Months }\end{array}$ & $\begin{array}{l}\text { P } 3 \text { Months } \\
-6 \text { Months }\end{array}$ & $\begin{array}{l}\text { P Baseline } \\
-6 \text { Months }\end{array}$ \\
\hline$\%$ Macroalbuminuria & $12.5 \%$ & - & - & & & \\
\hline \% Retinopathy & $16.1 \%$ & - & - & & & \\
\hline \% Neuropathy & $27.9 \%$ & - & - & & & \\
\hline \% Macrovascular Complications & $26.3 \%$ & - & - & & & \\
\hline \multicolumn{7}{|l|}{ Comorbidities } \\
\hline \% Hypertension & $80.4 \%$ & & & & & \\
\hline$\%$ Heart Failure & $4.8 \%$ & & & & & \\
\hline \% Atrial Fibrillation & $6.0 \%$ & & & & & \\
\hline$\%$ Other comorbidities & $23.9 \%$ & & & & & \\
\hline $\begin{array}{l}\text { Metabolic Disorders } \\
\text { (E.G Dyslipidaemia) }\end{array}$ & $58.7 \%$ & & & & & \\
\hline $\begin{array}{l}\text { Endocrine Disorders } \\
\text { (E.G. Hypothyroidism) }\end{array}$ & $26.0 \%$ & & & & & \\
\hline $\begin{array}{l}\text { Musculoskeletal Disorders } \\
\text { (E.G. Osteoporosis) }\end{array}$ & $13.5 \%$ & & & & & \\
\hline
\end{tabular}

Raw mean $( \pm S D)$ are presented for variables with normal distribution, raw median (25th-75th percentile) are presented for variables with deviations from the normal distribution and number and per cent of respondents are presented for dichotomous variables

$(*) \pm$ is calculated with $\mathrm{n}$ of 0 episodes excluded

(**) for part of the patients (\% less than $10 \%$ per case) information on diabetic complications was missing

\section{Questionnaires}

ADDQoL-19: Table 2 depicts the temporal variation of the parameters of the ADDQoL-19following the addition of insulin glargine to the treatment. At baseline, the mean \pm SD 'present QoL' score was $0.42 \pm 0.97$, reflecting "neither good nor bad" QoL. The mean \pm SD 'If no Diabetes' QoL score was $-1.50 \pm 0.78$, reflecting "a little better to a much better" QoL. The AWI score \pm SD was $-2.48 \pm 1.83$, indicating an overall negative impact of diabetes on QoL. QoL score was significantly lower by the presence of specific complications such as retinopathy $\left(\chi^{2}\right.$ test $\left.=11.2, \mathrm{p}=0.01\right)$ or macrovascular complications $\left(\chi^{2}\right.$ test $=8.5, p=0.02$ ). Patients who did not have these two complications declared a better QoL score in a higher percentage than the rest of the patients.

Table 2 Quality of life-ADDQoL-19 and the temporal variation of the effects of diabetes on quality of life parameters of ADDQoL-19

\begin{tabular}{lllll}
\hline & $\begin{array}{l}\text { Baseline } \\
\text { Mean(S.D) }\end{array}$ & $\begin{array}{l}\text { 3Months } \\
\text { Mean(S.D) }\end{array}$ & $\begin{array}{l}\text { 6Months } \\
\text { Mean(S.D.) }\end{array}$ & $\begin{array}{l}\text { P(6Months Vs } \\
\text { Baseline) }\end{array}$ \\
\hline Present Qol & $0.42(0.97)$ & $0.79(0.8 I)$ & $0.93(0.82)$ & $<0.00 I$ \\
If No Diabetes Qol Would Be & $-1.50(0.78)$ & $-1.5 I(0.78)$ & $-1.42(0.80)$ & 0.03 \\
Average Weighted Impact Score & $-2.48(I .83)$ & $-2.46(I .67)$ & $-2.35(I .7 I)$ & 0.03 \\
Parameters & & & & \\
I - Free-Time Activities & -2.57 & -2.48 & -2.26 & 0.002 \\
2 - Work Life & -3.01 & -2.91 & -2.57 & 0.028 \\
3 - Transportation/Long Journeys & -2.39 & -2.29 & -2.19 & 0.05 I \\
4 -Vacations & -2.58 & -2.6 & -2.48 & 0.735 \\
5 - Physical Ability & -2.97 & -2.84 & -2.66 & $<0.001$ \\
6 - Family Life & -2.76 & -2.58 & -2.47 & 0.007 \\
7 - Friendships And Social Life & -2.12 & -2.16 & -1.98 & 0.213 \\
8 - Intimate Personal Relationship & -2.45 & -2.44 & -2.44 & 0.814 \\
9 - Sex Life & -3.4 & -3.46 & -3.25 & 0.555 \\
I0 -Appearance & -1.58 & -1.59 & -1.52 & 0.586 \\
II - Self Esteem & -2.55 & -2.42 & -2.26 & 0.004 \\
\hline
\end{tabular}

Citation: Koukoulis G, Melidonis A, Milios K, et al. Quality of life of insulin-naïve people with type 2 diabetes mellitus inadequately controlled on oral antidiabetic drugs after the addition of insulin glargine, in every day clinical practice in Greece.J Diabetes Metab Disord Control. 20I5;2(2):72-80. 


\begin{tabular}{|c|c|c|c|c|}
\hline & $\begin{array}{l}\text { Baseline } \\
\text { Mean(S.D) }\end{array}$ & $\begin{array}{l}\text { 3Months } \\
\text { Mean(S.D) }\end{array}$ & $\begin{array}{l}\text { 6Months } \\
\text { Mean(S.D.) }\end{array}$ & $\begin{array}{l}\text { P(6Months Vs } \\
\text { Baseline) }\end{array}$ \\
\hline I2 - Motivations For Life & -2.44 & -2.44 & -2.36 & 0.327 \\
\hline I3 - Reaction Of Patients & -1.06 & -1.08 & -1.05 & 0.954 \\
\hline 14 - Feelings For The Future & -2.6 & -2.56 & -2.45 & 0.173 \\
\hline I5 - Financial Situation & -1.84 & -1.99 & -1.91 & 0.197 \\
\hline 16 - Living Conditions & -2.33 & -2.31 & -2.28 & 0.494 \\
\hline I7 - Lack Of Need For Dependence On Others & -2.27 & -2.27 & -2.36 & 0.214 \\
\hline I8 - Freedom To Eat As They Please & -4.08 & -4.03 & -3.79 & 0.035 \\
\hline 19 - Freedom To Drink As They Please & -3.31 & -3.26 & -3.15 & 0.196 \\
\hline
\end{tabular}

The 19 item scores are rated from -9 to +3 , where negative numbers indicate negative impact of diabetes on that aspect of life. Rows in darker grey represent the domains with negative impact of diabetes on those aspects of life

At 6 months with the use of Friedman Test, the 'present QoL' score increased by 0.51 points from baseline (3months score $0.79 \pm 0.81$, 6 months score $0.93 \pm 0.82, p<0.001)$ reflecting "good" QoL, the "If no Diabetes' QoL score increased by 0.08 points (3months score $-1.51 \pm 0.78$, 6months score $-1.42 \pm 0.80, p=0.03$ ) reflecting "a little better" QoL and the AWI score increased by 0.13 points (3months score $-2.46 \pm 1.67,6$ months score $-2.35 \pm 1.71, p=0.03$ ), indicating an overall less negative impact of diabetes on QoL.

There was an improvement in 17 out of 19 parameters of ADDQoL-19 between 6months and baseline and the change was significant in 6 parameters $(p<0.05)$. There was a negative impact of diabetes in 2 parameters of ADDQoL-19 concerning the financial situation and the need for dependence on others between 6months and baseline as shown in Table 2. Both at 3 and 6 months patients

Table 3 Diabetes Treatment Satisfaction Questionnaire-DTSQs with retinopathy and macrovascular complications scored lower on the QoL compared to patients without the respective complications. There were no significant associations between comorbidities and QoL scores.

DTSQs: Table 3 summarizes the results of the DTSQs score. TS at baseline was high in this population, with a mean DTSQ score of $22.58 \pm 7.13$. At 6 months with the use of Friedman Test, DTSQ score showed a progressive improvement from baseline and increased by 4.52 points (3months score $26.34 \pm 6.51$, 6months score $27.10 \pm 6.86$, $p<0.001)$. A statistically significant lower satisfaction with treatment was detected by t-test in patients that had macroalbuminuria $(\mathrm{p}=0.02)$ and retinopathy $(p<0.01)$ and in patients suffering from other comorbidities such as metabolic, endocrine and musculoskeletal disorders, $(\mathrm{p}=0.01)$.

\begin{tabular}{lllll}
\hline & Baseline Mean(S.D) & 3Months Mean(S.D) & 6Months Mean(S.D.) & P(6Months Vs Baseline) \\
\hline Treatment Score & $22.58(7.13)$ & $26.34(6.5 \mathrm{I})$ & $27.10(6.86)$ & $<0.001$ \\
Hypo/Hyperglycaemia Score & $5.22(1.89)$ & $3.82(2.11)$ & $3.20(2.12)$ & $<0.001$
\end{tabular}

Perceptions of blood glucose control: As shown in Table 3, perceived frequency of hypo/hyperglycaemia score was lower at 6months (3.20 \pm 2.12$)$ and at 3months (3.82 \pm 2.11$)$ vs baseline $(5.22 \pm 1.89)$ and became statistically significant at 6 months vs baseline $(p<0.001)$.

DTSQc: Table 4 summarizes the results of the DTSQc score. The DTSQc score was $11.45 \pm 6.70 \quad(p<0.001)$, reflecting a greater improvement in TS over the 6months.

Table 4 Diabètes Treatment Satisfaction Questionnaire-DTSQc

\begin{tabular}{lll}
\hline & Mean(S.D) & P \\
\hline Treatment Score & II.45(6.70) & 0.001 \\
Hypo/Hyperglycaemia Score & $-2.74(2.73)$ & 0.001 \\
\hline
\end{tabular}

Perceptions of blood glucose control: As shown in Table 4, the respective hypo/hyperglycaemia score was $-2.74 \pm 2.73,(p<0.001)$, reflecting fewer problems with blood glucose levels with treatment over the 6 months.

\section{Daily insulin use}

An increase of insulin glargine dosage was recorded over time. At 3 months the mean daily dosage was 23.2 Units, while at 6 months it was 25.8Units from 17.6Units at baseline.

\section{Efficacy of treatment and changes in body weight and BMI}

Before insulin initiation, mean $\mathrm{HbAlc}(\%) \pm$ SDwas $8.3 \pm 0.5$, confirming a need for therapy intensification and decreased to a mean of $7.4 \pm 0.7$ and $7.2 \pm 0.6$ at 3 and 6 months, (Wilcoxon Test, $p<0.001$ ). $34.2 \%$ of participants $(n=141)$ met the target of $\mathrm{HbAlc}<7 \%$ at 6 months. The correlations between glycaemic control, as expressed by $\mathrm{HbAlc}$ values and the QoL indices, in all the three time landmarks of the study (baseline, 3months and 6months), are shown in Table 5.

Table 5 Quality of life ADDQoL-19 and glycaemic control correlations

\begin{tabular}{llll}
\hline & Baseline(r) & 3Months(r) & 6Months $(r)$ \\
\hline Correlation coefficient & 0.17 & 0.19 & 0.19 \\
$P$ & $<0.01$ & $<0.01$ & $<0.01$ \\
\hline
\end{tabular}

ADDQoL, audit of diabetes dependent quality of life; DTSQs/c, diabetes treatment satisfaction questionnaire status/change; QoL, quality of life; TS, treatment satisfaction

Mean FPG $(\mathrm{mg} / \mathrm{dl}) \pm$ SD showed a similar pattern, falling from $189( \pm 43) \mathrm{mg} / \mathrm{dl}$ atbaseline to $137( \pm 30) \mathrm{mg} / \mathrm{dl}$ at 3 months and $128( \pm 32)$ $\mathrm{mg} / \mathrm{dl}$ at 6 months (Paired t-Test, $p<0.001$ ). 
There were no significant changes in mean weight and mean BMI during the study period (Table 1).

\section{Hypoglycaemic episodes}

The number of documented symptomatic and serious hypoglycaemic episodes at 3 and 6months are described in Table 1. For symptomatic hypoglycaemic events, a non-significant uptrend was observed between 3 and 6months. In total 164 symptomatic hypoglycaemic episodes were reported as adverse events and 102 of them $(62.2 \%)$ were related to insulin glargine. No severe hypoglycaemic episodes were observed. One serious adverse event, vacuities worsening, was reported and was not related to insulin glargine.

\section{Discussion}

The advent of insulin analogues and especially the basal insulin have facilitated initiation of insulin treatment and reduced the incidence of hypoglycaemic episodes which was a certain barrier for insulin therapy in the early stages of T2DM. ${ }^{15}$ The recent treatment guidelines suggested by the American Diabetes Association (ADA) and the European Association for the Study of Diabetes (EASD) and the introduction of simple instructions for insulin titration consider that basal insulin is usually the optimal initial regimen for patients with T2DMinadequately controlled on OADs. ${ }^{6,16,17}$

The results of this 6month observational non interventional study, showed high compliance rate with the treatment and benefits in both glycaemic control and health related QoL. An overall mean decrease of $\mathrm{HbAlc}$ of $1.1 . \%$ from $8.3 \%$ to $7.2 \%$ was observed at 6 months, almost at the recommended goal of $7 \%$, with $34.2 \%$ of the participants reaching the target of $\mathrm{HbA} 1 \mathrm{c}<7 \%$. No significant changes in body weight or BMI were recorded from baseline to study end. Throughout the study, no significant changes were observed in the coadministration of the antidiabetic and other medication.

The actual glycaemic improvement achieved during the study was accompanied with a positive impact on TS and general QoL without complaints related to hypoglycaemia or hyperglycaemia. The results of QoL confirm previously reported data from both observational and randomized clinical studies with the same or longer follow up. ${ }^{5,7,16,18}$

In accordance with our study, the Canadian INSIGHT trial suggested that improving glucose control by adding insulin glargine to OAD therapy in patients with T2DM had a positive impact on TS and general QoL without complaints related to hypoglycaemia.?

Another Dutch observational study also reported improvement of glycaemic control and health related QoL following initiation of insulin glargine in patients with T2DM sub-optimally controlled on oral therapy in routine primary care. ${ }^{8}$

QoL and DTQS score were significantly reduced by the presence of specific complications such as retinopathy or macrovascular complications. This is consistent with previous finding that the presence of diabetic complications, particularly the presence of two or more complications is associated with worsened QoL. ${ }^{1}$

The strength of this observational study is that it examined every day clinical practice with adequate statistical power and external validity. This study was conducted in a large and heterogeneous sample treated by diabetologists, internists, endocrinologists in hospital outpatient clinics, primary care and private practice, across different regions of the country, indicating a degree of representativeness of available management of patients with T2DM.
The possibility though, that part of the improvements might be related to a study effect cannot be excluded, with limitations being the non-randomised study design and absence of control group and lack of a method to evaluate the compliance of the patients to the treatment. Moreover since the study did not interfere with clinical practice, insulin titration schedule and diet modification were left to the clinical judgement of the participating physicians and blood samples were collected and measured locally by the participating centres.

In accordance with glycaemic control, the observed improvements in health-related QoL and TS at 3months were sustained at 6months following insulin initiation. It would seem highly unlikely that these changes are simply attributable to an expectancy effect. In fact, we may assume that the opposite has occurred; patients have experienced real benefits and symptoms relief following insulin initiation.

Our findings ideally should be confirmed by a randomized clinical trial over an extended period to establish longer-term effects, although they are indicative of an association between improvement of $\mathrm{HbA} 1 \mathrm{c}$ by initiation of insulin glargine and improvement of QoL and TS.

\section{Conclusion}

In conclusion and taking into consideration the limitations, the present observational study, conducted in diabetic centers in Greece over a 6 months period supports that the initiation of insulin glargine in patients with T2DM sub-optimally controlled on oral therapy, can improve glucose control and have a positive impact on health related QoL and TS with reduced perception of hypo/hyperglycemia and without significant changes in body weight. Our findings add to the literature concerning QoL, TS and glycemic control and combat the generally observed delay of insulin therapy in routine daily medical practice in the country. It may be proved helpful for patients with diabetes and health care providers to appreciate the potential value of insulin glargine addition to the treatment of diabetes and its effect on the QoL and TS indices. ${ }^{2}$

\section{Acknowledgements}

Editorial support was provided by Ass. Professor Georgios Koukoulis, University Clinic of Endocrinology and Metabolic Conditions, University Hospital of Larisa, Larisa, Greece and Dr Andreas Melidonis, Diabetic Centre, Outpatient Clinic, General Hospital of Piraeus «Tzaneio», Piraeus, Greece.

\section{Funding}

The study and the editorial support were funded by Sanofi, Greece.

\section{Authors contributions}

GK was principal investigator, study co-ordinator and investigator, and provided editorial support for the manuscript. AM was study coordinator, and provided editorial support for the manuscript. KM was study-sponsor coordinator. All other study investigators conducted the study and collected the data.

\section{Conflict of interest}

Ass. Prof. Georgios Koukoulis has received research support and/ or consulting honoraria from Sanofi and Novartis and has no other relevant affiliation or financial involvement with any organization or entity with a financial interest in or financial conflict with the subject matter or materials discussed in the manuscript apart from those disclosed. 
Dr. Andreas Melidonis has received research support and/or consulting honoraria from Sanofi, Novartis and Novo and has no other relevant affiliation or financial involvement with any organization or entity with a financial interest in or financial conflict with the subject matter or materials discussed in the manuscript apart from those disclosed.

Kostas Milios is an employee of Sanofi working as Medical Scientific Liaison for Greece

\section{Mellita investigators}

\section{Study Co-Ordinators:}

\section{a. Ass. Prof. Georgios Koukoulis}

University Clinic of Endocrinology and Metabolic Diseases, University Hospital of Larisa - Larisa, Greece

\section{b. Dr. Andreas Melidonis}

Diabetic Centre, Outpatient Clinic, General Hospital of Piraeus «Tzaneio», Piraeus, Greece

Study investigators:

i. Dr. Dimitrios Boutel, Outpatient Diabetic Clinic, General Hospital of Giannitsa, -Giannitsa, Greece

ii. Dr. Georgios Chaliotis, Department of Internal Medicine, General Hospital of Chalkida, -Chalkida, Greece

iii. Dr. Ioanna Chrisanthakopoulou, Internist - Diabetologist, Thessaloniki, Greece

iv. Dr. Eftichia Dimou, Department of Internal Medicine, General Hospital of Samos "Agios Panteleimon"- Samos, Greece

v. Dr. Georgios Georgakopoulos, Dr. Panagiotis Mantas andDr. Themistoklis Spaidiotis Department of Internal Medicine, General Hospital of Thiva, -Thiva, Greece

vi. Dr. Maria Kalapodi and Dr. Christos Bikas, Department of Internal Medicine, General Hospital of Pyrgos, Pyrgos, Greece

vii. Dr. Vasilis Klisiaris, Department of Internal Medicine, General Hospital of Larisa "Koutllibanio-Triantafilio"- Larisa, Greece

viii. Ass. Prof. Georgios Koukoulis and Dr. Ioannis Goudios, University Clinic of Endocrinology and Metabolic Diseases, University Hospital of Larisa - Larisa, Greece

ix. Dr. Maria Kouroglou, Department of Internal Medicine, General Hospital of Mytilene "Vostanio"- Mytilene, Greece

x. Dr. Dimitrios Makrigiannis, Department of Internal Medicine, General Hospital of Ioannina "Hatzikosta" - Ioannina, Greece

xi. Dr. Ioannis Mallias, Second Department of Internal Medicine, General Hospital of Serres - Serres, Greece

xii. Dr. Georgios Marathonitis, Department of Internal Medicine, General Hospital of Melissia - Athens, Greece

xiii. Dr. Athanasios Michalopoulos, Internist - Diabetologist, Corfu, Greece

xiv. Dr. Stefanos Papantoniou, Department of Internal Medicine, General Hospital of Kavala - Kavala, Greece xv. Dr. Aggelos Pappas and Dr. Evridiki Kirlaki, Department of Internal Medicine, General Hospital of Heraklio "VenizelioPananio"- Heraklio, Greece

xvi. Ass. Prof. Melpomeni Peppa, Research Unit and Diabetic Centre, 2nd Propaedeutic and Internal Medicine, University Hospital of Athens "ATTIKON", Athens, Greece

xvii. Dr. Georgios Piaditis and Dr. Labrini Papanastasiou, Endocrinology Department and Diabetic Centre, General Hospital of Athens "G. Gennimatas" - Athens, Greece

xviii. Dr. Georgia Talabouka, Internist-Diabetologist, Patra, Greece

xix. Dr. El Hasban Taisir, Health Centre of Elefsina,- Elefsina, Greece

xx. Dr. Ioannis Zacharos, Internist - Diabetologist, Piraeus, Greece

\section{References}

1. Rubin RR, Peyrot M. Quality of life and diabetes. Diabetes Metab Res Rev. 1999;15(3):205-218.

2. Susan NL. Health-related Quality of Life among Adults with Diabetes Current Diabetes Reports. 2005;5(2):124-130.

3. Kuznetsov L, Griffin SJ, Davies MJ, et al. Diabetes-specific quality of life but not health status is independently associated with glycaemic control among patients with type 2 diabetes: A cross-sectional analysis of the ADDITION-Europe trial cohort. Diabetes Res Clin Pract. 2014;104(2):281-287.

4. Hartman I. Insulin Analogs: Impact on Treatment Success, Satisfaction, Quality of Life and Adherence. Clin Med Res. 2008;6(2):54-67.

5. Hajos TR, Pouwer F, Grooth R, et al. The longitudinal association between glycaemic control and health-related quality of life following insulin therapy optimisation in type 2 diabetes patients. A prospective observational study in secondary care. Qual Life Res. 2012;21(8):1359-1365.

6. Inzucchi SE, Bergenstal RM, Buse JB, et al. Management of Hyperglycemia in Type 2 Diabetes: A Patient-Centered Approach Position Statement of the American Diabetes Association (ADA) and the European Association for the Study of Diabetes (EASD). Diabetes Care. 2012;35(6):1364-1379.

7. Houlden R, Ross S, Harris S, et al. Treatment satisfaction and quality of life using an early insulinization strategy with insulin glargine compared to an adjusted oral therapy in the management of Type 2 diabetes: The Canadian INSIGHT Study. Diabetes Res Clin Pract. 2007;78(2):254-258

8. Hajos TR, Pouwer F, de Grooth R, et al. Initiation of insulin glargine in patients with type 2 diabetes in suboptimal glycaemic control positively impacts health-related quality of life. A prospective cohort study in primary care. Diabet Med. 2011;28(9):1096-1102.

9. http://ec.europa.eu/health/human-use/clinical-trials/index_en.ht

10. Andrews EA, Avorn J, Bortnichak EA, et al. Guidelines for Good Epidemiology Practices for drug, Device, and Vaccine Research in the United States. Pharmacoepidemiol Drug Saf. 1996;5(5):333-338.

11. IEA European Federation. Good Epidemiological Practice (GEP) proper conduct in epidemiology research. 2004.

12. Workgroup on Hypoglycemia, American Diabetes Association (ADA) Defining and Reporting Hypoglycemia in Diabetes: A report from the American Diabetes Association Workgroup on Hypoglycemia. Diabetes Care. 2005;28(5):1245-1249. 
13. Health Psychology Research LTD. UK; 2013.

14. Witthaus E, Stewart J, Bradley C. Treatment satisfaction and psychological well-being with insulin glargine compared with NPH in patients with Type 1 diabetes. Diabet Med. 2001;18(8):619-625.

15. Rosenstock J, Dailey G, Massi-Benedetti M, et al. Reduced hypoglycemia risk with insulin glargine: A meta-analysis comparing insulin glargine with human NPH insulin in type 2 diabetes. Diabetes Care. 2005;28(4):950-955.

16. Riddle MC, Rosenstock J, Gerich $\mathrm{J}$, et al. The treat-to-target trial: Randomized addition of glargine or human NPH insulin to oral therapy of type 2 diabetic patients. Diabetes Care. 2003;26(11):3080-3086.
17. Inzucchi SE, Bergenstal RM, Buse JB, et al. Management of Hyperglycemia in Type 2 Diabetes: A Patient-Centered Approach: Update to a Position Statement of the American Diabetes Association and the European Association for the Study of Diabetes. Diabetes Care. 2015;38(1):140-149.

18. Bradley C, Plowright R, Stewart J, et al. The Diabetes Treatment Satisfaction Questionnaire change version (DTSQc) evaluated in insulin glargine trials shows greater responsiveness to improvements than the original DTSC. Health and Qual Life Outcomes. 2007;5:57. 